\title{
Alterações histológicas em fígados e linfonodos de búfalos (Bubalus bubalis) mantidos em pastagens de Brachiaria spp. ${ }^{1}$
}

\author{
Beatriz Riet-Correa², Franklin Riet-Correa ${ }^{3}$, Carlos Alberto de Oliveira Junior², \\ Valíria C. Duarte ${ }^{2}$ e Gabriela Riet-Correa2 ${ }^{*}$
}

\begin{abstract}
Riet-Correa B., Riet-Correa F., Oliveira Junior C.A., Duarte V.C. \& Riet-Correa G. 2010. [Histologic lesions in livers and lymph nodes in buffalo (Bubalus bubalis) grazing in Brachiaria spp. pastures.] Alterações histológicas em fígados e linfonodos de búfalos (Bubalus bubalis) em pastagens de Brachiaria spp. Pesquisa Veterinária Brasileira 30(9):705-711. Faculdade de Medicina Veterinária, Universidade Federal do Pará, Rua Maximino Porpino da Silva 1000, Castanhal, PA 68743-080, Brazil. E-mail: griet@ ufpa.br

Infiltration by foamy macrophages and other lesions are reported in healthy cattle held in Brachiaria spp. pastures. With the objective to study histologic lesions in the liver and mesenteric lymph nodes in buffalo in the state of Pará, samples of liver and lymph nodes of 142 buffalo Murah and 15 Nelore cattle were studied histologically. The samples were collected in an slaughterhouse and divided into groups of animals according to their origin and period of grazing Brachiaria spp. pastures. Group (G) 1 consisted of 79 buffalo from Marajó Island, raised in native pastures free of Brachiaria spp.; G2 was composed of 17 buffalo kept since birth in Brachiaria brizantha pastures; G3 was composed of 29 buffalo purchased in Marajó Island and introduced in $B$. decumbens pastures where they stayed for nearly 12 months; G4 consists of 17 buffalo purchased in Marajó Island and introduced in B. brizantha pastures where they stayed for nearly 18 months. G5 was composed of 15 Nelore cattle grazing $B$. brizantha during one year period. To assess the degree of liver injury, grades following a scale of 0 to 4 were established according to the quantity and size of groups of foamy macrophages. In G1, from the Marajó Island, there were no significant histological changes in liver and lymph nodes. Foamy macrophages and other lesions were observed in liver and lymph nodes of all samples from G1, G2, G3, and G4. The animals from G2 and G4, which remained a longer period in Brachiaria spp., showed more pronounced infiltration of foamy macrophages $(P<0.05)$ than the animals of $G 3$. Other lesions observed in the livers of these three groups were swollen, vacuolated or necrotic hepatocytes, mainly in the centrolobular region, and thickening of the Glisson's capsule with vacuolization and necrosis of subcapsular hepatocytes. These lesions were more pronounced in areas where exists higer infiltration of foamy macrophages. In cattle from G5 smaller groups of foamy macrophages were observed in the lymph nodes and were absent in the liver. These results suggest that the hepatic lesions observed in buffalo are caused by ingestion of Brachiaria spp. The presence of severe lesions in buffalo without clinical signs, much more severe than those observed and reported previously in cattle, as well as the low frequency of Brachiaria poisoning in buffalo grazing in Brachiaria spp. pastures, suggest that buffalo are resilient to Brachiaria spp. poisoning. In each group, there was no association between the weight at slaughter and the degree of lesion. It is also suggested that the observation of severe lesions of the liver,
\end{abstract}

\footnotetext{
${ }^{1}$ Recebido em 23 de fevereiro de 2010.

Aceito para publicação em 10 de abril de 2010.

2 Faculdade de Medicina Veterinária, Universidade Federal do Pará (UFPA), Campus de Castanhal, Rua Maximino Porpino da
}

Silva 1000, Castanhal, PA, 68743-080, Brasil. *Autor para correspondência: griet@ufpa.br

${ }^{3}$ Hospital Veterinário, Campus de Patos da Universidade Federal de Campina Grande, Patos, PB 58700-000, Brasil. 
similar to those observed in this experiment, in animal that died from other diseases, can lead to a wrong diagnosis of Brachiaria poisoning.

INDEX TERMS: Liver, lymph nodes, histologic changes, buffalo, Brachiaria spp., saponins, foamy macrophages.

RESUMO.- Infiltração por macrófagos espumosos e outras lesões podem ser encontradas em bovinos clinicamente sadios em pastagens de Brachiaria spp. Com o objetivo de determinar as alterações histológicas do fígado e linfonodos mesentéricos em búfalos no Pará foram estudadas as alterações histológicas de fragmentos desses órgãos de 142 búfalos da raça Murrah e de 15 bovinos da raça Nelore, coletados em frigoríficos. As coletas foram separadas em grupos de animais de acordo com sua origem e tempo de permanência na pastagem de Brachiaria spp., sendo o Grupo $(G) 1$ composto por 79 búfalos provenientes da llha de Marajó, criados em pastagens de campo nativo; o G2 composto por 17 búfalos mantidos desde o nascimento em pastagens de Brachiaria brizantha; o G3 composto por 29 búfalos adquiridos na llha do Marajó e introduzidos em pastagem de $B$. decumbens por aproximadamente 12 meses; o G4 composto por 17 búfalos adquiridos na llha de Marajó e introduzidos em pastagem de $B$. brizantha por aproximadamente 18 meses; e o G5 composto por 15 bovinos mantidos em pastagem de $B$. brizantha por aproximadamente 12 meses. Para avaliar a gravidade da lesão hepática foram estabelecidos graus de acordo com a quantidade e tamanho dos grupos de macrófagos espumosos, seguindo uma escala de 0 a 4. Nos animais do G1, provenientes da Ilha de Marajó, não foram observadas alterações histológicas significativas no fígado e linfonodos mesentéricos. Em todas as amostras dos grupos G2, G3 e G4 foram observados quantidades variáveis de macrófagos espumosos no fígado e linfonodos mesentéricos. Os animais dos grupos G2 e do G4, que permaneceram um período maior em pastagens de Brachiaria spp, apresentaram lesões mais acentuadas $(\mathrm{P}<0,05)$ de macrófagos espumosos do que os animais do G3. Além da presença de macrófagos espumosos, foram observadas também, no fígado desses três grupos, tumefação, vacuolização e necrose de hepatócitos, principalmente da região centrolobular. Essas lesões eram mais acentuadas nas áreas onde havia maior infiltração de macrófagos espumosos. Havia fibrose capsular e as lesões dos hepatócitos nesta localização eram mais severas. Nos bovinos do G5 foram observados pequenos grupos de macrófagos espumosos nos linfonodos mesentéricos e ausência dessas células no fígado. Esses resultados sugerem que as lesões hepáticas observadas na histologia em búfalos sem sinais clínicos são ocasionadas pela ingestão de Brachiaria spp. A presença de lesões severas em búfalos sem sinais clínicos, bem mais graves do que as observadas em bovinos, assim como a ausência de surtos de intoxicação por Brachiaria nessa espécie, sugere sua resiliência à intoxicação por Brachiaria spp. Dentro de cada grupo não foi comprovada associação entre o peso ao abate e a gravidade das lesões. A presença de lesões severas no fígado de búfalos sem sinais clínicos alerta para o fato de que lesões semelhantes encontradas durante necropsias de búfalos mortos por outras causas possam levar ao diagnóstico errado de intoxicação por Brachiaria spp.

TERMOS DE INDEXAÇÃO: Fígado, linfonodo, alterações histológicas, búfalos, Brachiaria spp., saponinas, macrófagos espumosos.

\section{INTRODUÇÃO}

A intoxicação por Brachiaria decumbens, B. brizantha e $B$. humidicola afeta bovinos (Fagliari et al. 1993, Lemos et al.1996 a 1997) ovinos (Lemos et al. 1996b, Brum et al. 2007) caprinos (Lemos et al.1998, Silveira et al. 2009) e bubalinos (Rozza et al. 2004) e ocorre em qualquer época do ano. Os ovinos são mais suscetíveis do que os bovinos à intoxicação. Os animais jovens (cordeiros e bezerros) são mais suscetíveis do que os adultos (Riet-Correa \& Méndez 2007). A intoxicação pode ocorrer, também, em animais lactentes, com menos de 30 dias de idade (Fagliari et al. 1983, Lemos et al. 1996a).

No Pará, $B$. brizantha é a pastagem mais utilizada para bovinos e bubalinos, seguida da $B$. humidicola. A intoxicação por $B$. brizantha nesse estado tem sido observada em bovinos (Barbosa 2009), ovinos (Albernaz et al. 2008) e caprinos (Silveira et al. 2009) e a intoxicação por B. humidicola foi relatada em eqüinos (Barbosa et al. 2006).

Tokarnia \& Langenegger (1983) em um estudo para averiguar uma doença de etiologia desconhecida em búfalos pastejando em B. humidicola, em Manaus, encontraram, na histopatologia do fígado vacuolização, tumefação e necrose de hepatócitos, e grande número de células tumefeitas, com citoplasma mais claro e espumoso (macrófagos espumosos), diagnosticando fotossensibilização hepatógena. Recentemente foi diagnosticado um caso da intoxicação por $B$. brizantha em um bubalino que apresentava sinais de encefalopatia hepática, caracterizados por depressão acentuada, permanência em decúbito esternal, paralisia da mandíbula, língua e pálpebras e cegueira. Na necropsia foi observado fígado aumentado de tamanho, com bordos arredondados e com acentuação do padrão lobular. Histologicamente o fígado apresentava grande quantidade de macrófagos espumosos distribuídos por todo o parênquima hepático, discreta proliferação de células de ductos e fibrose na região periportal. Havia, também, vacuolização da substância branca no tronco encefálico (Dados não publicados). Em materiais de bubalinos recebidos no Laboratório de Patologia da Faculdade de Medicina Veterinária da Universidade Federal do Pará (UFPA), que morreram de diversas causas, foi observado no fígado e linfonodos de todos os animais grande quantidade de macrófagos espumosos (G. RietCorrea 2009, dados não publicados). No Rio Grande do Sul, Rozza et al. (2004) descrevem um caso de intoxicação por 
$B$. decumbens em uma búfala em que as principais alterações histopatológicas do fígado consistiam de degeneração e necrose de hepatócitos, proliferação de ductos biliares, bilestase, e presença de cristais biorrefringentes no interior dos macrófagos, hepatócitos e ductos biliares.

Infiltração focal de macrófagos com citoplasma espumoso tem sido descrita em fígado e linfonodos de bovinos mantidos em pastagem de Brachiaria spp. (Driemeier et al. 1998, Fioravanti 1999, Gomar et al. 2005, Moreira et al. 2009). Em bovinos, foi encontrada correlação negativa entre os ganhos de peso e o número de macrófagos espumosos no fígado de bovinos pastejando em $B$. decumbens, sugerindo que perdas econômicas importantes ocorrem em animais sem sinais clínicos pastejando essa gramínea (Fioravanti 1999). Emagrecimento progressivo e morte, após alguns meses, foram observados em bovinos mantidos em pastagens de $B$. decumbens, sem fotossensibilização. Nesse caso um animal necropsiado apresentava grande quantidade de macrófagos espumosos no fígado, baço, linfonodos mesentéricos e hepáticos e na submucosa do intestino delgado (Riet-Correa et al. 2002).

Considerando a importância da bubalinocultura para a região Norte do Brasil, assim como o fato de que as principais forrageiras introduzidas nesta região são diferentes espécies de braquiária é evidente a necessidade de estudar a intoxicação clínica e subclínica por esta gramínea em búfalos. Os objetivos desse trabalho foram: determinar as alterações histológicas do fígado e linfonodos mesentéricos em bubalinos no Pará; determinar se há associação entre a presença de macrófagos espumosos no fígado e linfonodos e outras lesões histológicas do fígado com a ingestão de Brachiaria spp. e determinar se, em búfalos, as alterações hepáticas causadas pelas diferentes espécies de Brachiaria representam uma forma subclínica da intoxicação.

\section{MATERIAL E MÉTODOS}

Para realizar este trabalho foram coletados fragmentos de fígado e linfonodos mesentéricos de 142 búfalos (Bubalus bubalis) da raça Murrah e de 15 bovinos da raça Nelore abatidos em frigoríficos localizados nos municípios de Belém e Castanhal, Pará. O material coletado foi processado para estudo histológico no Laboratório de Patologia da Faculdade de Medicina Veterinária da UFPA.

As coletas foram separadas em grupos de animais de acordo com sua origem e tempo de permanência em pastagem de Brachiaria spp. Após o abate buscaram-se informações junto aos proprietários dos animais para realização de questionário no qual se identificava a origem dos animais, tipo de pastagem em que estavam, tempo de permanência desses animais na pastagem, idade, e se havia algum histórico de doença de pele (fotossensibilização) na propriedade.

O Grupo 1 de coleta (G1) era composto por 79 animais, sem idade definida, provenientes de municípios localizados na Ilha de Marajó, onde foram criados em pastagens de campo nativo não tendo permanecido em pastagens de Brachiaria spp. O Grupo 2 (G2) era composto por 17 búfalos, com idade entre 3 e 4 anos, provenientes do município de Rondon do Pará, região Su- deste do Pará. Esses animais foram criados desde o nascimento em uma propriedade que utilizava somente Brachiaria brizantha como alimentação. Os Grupos 3 e 4 (G3 e G4) foram adquiridos na llha do Marajó e introduzidos em campos com pastagem de Brachiaria spp localizados no continente. O G3 era composto por 29 búfalos, com idade entre 24 e 30 meses, mantidos em pastagem predominante de $B$. decumbens por aproximadamente 12 meses, em propriedade localizada no município de Ourém, região Nordeste do estado do Pará. O G4 era composto por 17 búfalos, mantidos em pastagem com predominância de $B$. brizantha por aproximadamente 18 meses, em propriedade localizada no município de Paragominas, região Sudeste do Estado. $O$ G5 era composto por 15 bovinos com idade entre 34 e 36 meses, provenientes do município de Igarapé Açú, mantidos em pastagem de $B$. brizantha por aproximadamente 12 meses. Amostras desse grupo foram coletadas com o objetivo de comparar a gravidade das lesões hepáticas dos bovinos com as dos bubalinos.

Antes do abate eram inspecionados todos os animais para identificar lesões de fotossensibilização. Na linha de abate foram coletados fígado e linfonodos mesentéricos junto à mesa de inspeção veterinária e foi determinado o peso individual das carcaças.

O material coletado foi fixado em formal a $10 \%$, embebido em parafina, cortado a 4-5 micrômetros de espessura, corados pela hematoxilina-eosina e avaliados em microscópio de luz. Para avaliar o grau de lesão hepática foram estabelecidos graus de acordo com a quantidade e tamanho dos grupos de macrófagos espumosos, seguindo uma escala de 0-4: grau 0 = ausência de macrófagos espumosos; grau 1 = de 1-70 grupos pequenos de macrófagos espumosos compostos por 3-10 células, podendo conter grupos de até 50 células; grau 2 = até 300 grupos pequenos de macrófagos espumosos dos quais a maior parte continham de 5-30 células, com alguns grupos de até 100 células, principalmente na região centrolobular; grau $3=$ de 300-400 grupos de macrófagos espumosos, contendo de 10-30 células e alguns grupos com até 100 células, distribuídos pelo lóbulo; grau 4: grupos extensos de macrófagos espumosos, alguns com mais de 200 células, que começavam na região centrolobular e se estendiam até a região mediozonal, às vezes formando pontes entre as veias centrolobulares e infiltrando grande parte do lóbulo. Para a contagem foi utilizada uma lâmina histológica com um fragmento de fígado e outra com um fragmento de linfonodo para cada animal examinado. Para a contagem dos grupos de macrófagos no microscópio óptico foi utilizada objetiva de 10x e para contagem das células de cada grupo objetiva de 40x.

Para análise dos dados, foram geradas análises estatísticas usando o software Statistix 9.0. Foram usados os testes de Qui-quadrado para avaliação do grau de infiltração por macrófagos espumosos nos diferentes grupos e teste de KruskalWallis para avaliação do peso no abate em relação ao grau de infiltração por macrófagos espumosos em cada grupo. Foram realizadas também distribuições de freqüências para os graus das lesões nos diferentes grupos.

Durante o período de março de 2008 a janeiro de 2010 foram acompanhados e estudados os casos de fotossensibilização em búfalos diagnosticados na Faculdade de Veterinária da UFPA.

\section{RESULTADOS}

Em nenhum dos grupos foram observadas lesões de fotossensibilização. Nos animais do G1, provenientes da llha 
de Marajó, não foram observadas alterações histológicas significativas no fígado e linfonodos mesentéricos.

Em todas as amostras dos G2, G3 e G4 foram observados macrófagos espumosos no fígado (Fig.1 e 2) e linfonodos mesentéricos (Fig.3). Nos animais do G2 (nascidos e criados em Brachiaria brizantha) todos os animais tiveram algum grau de infiltração por macrófagos espumosos no fígado. Das 17 amostras três apresentaram grau 1, cinco grau 2, seis grau 3 e três grau 4, sendo observados grupos de macrófagos em todas as regiões do lóbulo. Os hepatócitos da região centrolobular estavam aumentados de volume, com citoplasma pálido e vacuolizado, membrana irregular e núcleo pequeno. Essas alterações eram mais acentuadas nos locais onde a infiltração de macrófagos era acentuada (grau 3 ou 4), podendo se estender por quase todo o lóbulo, restando apenas os hepatócitos próximos à região periportal sem alterações (Fig.2). Foi ob-

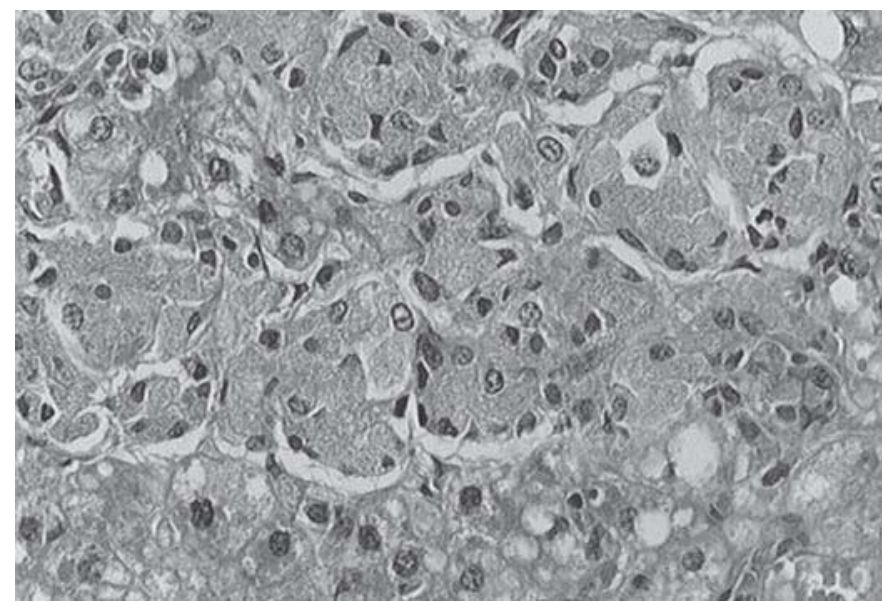

Fig.1. Grupo de macrófagos espumosos na região centrolobular do fígado de búfalo. Os hepatócitos adjacentes apresentam-se severamente vacuolizados. HE, obj.40x.

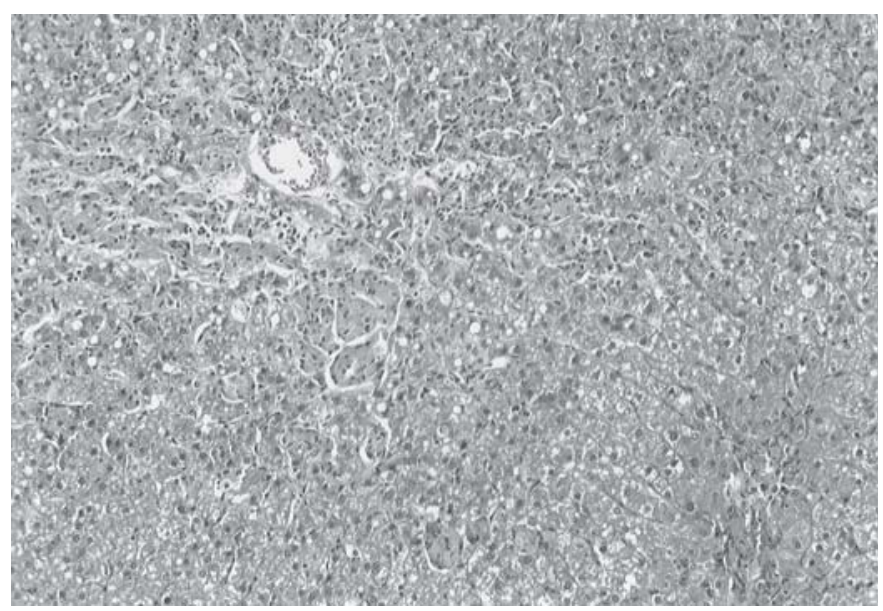

Fig.2. Grupos extensos de macrófagos espumosos infiltrando grande parte do lóbulo, no fígado de búfalo. Os hepatócitos apresentam-se tumefeitos, com citoplasma pálido e vacuolizado, membrana irregular e núcleo pequeno. HE, obj.40x.

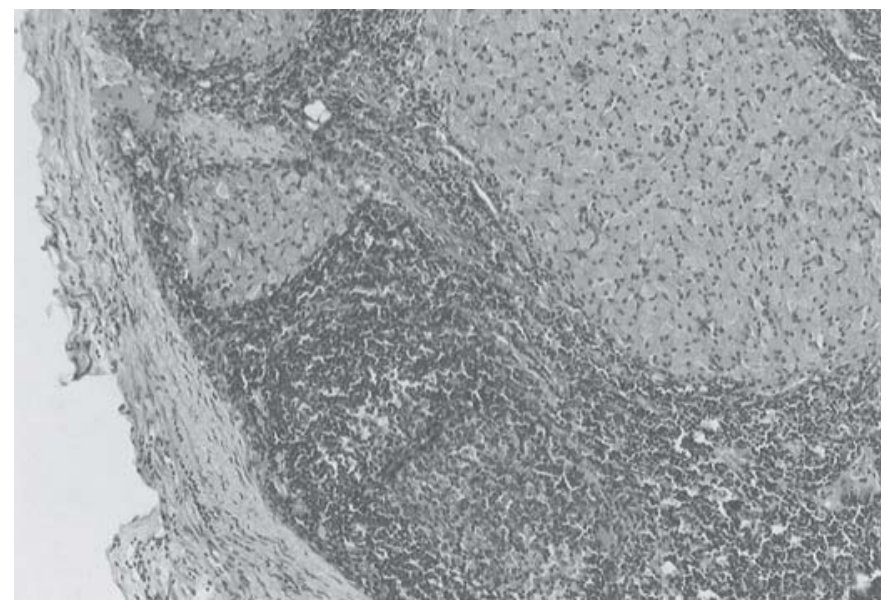

Fig.3. Grupos de numerosos macrófagos no córtex e medula de linfonodo de búfalo. HE, obj.40x.

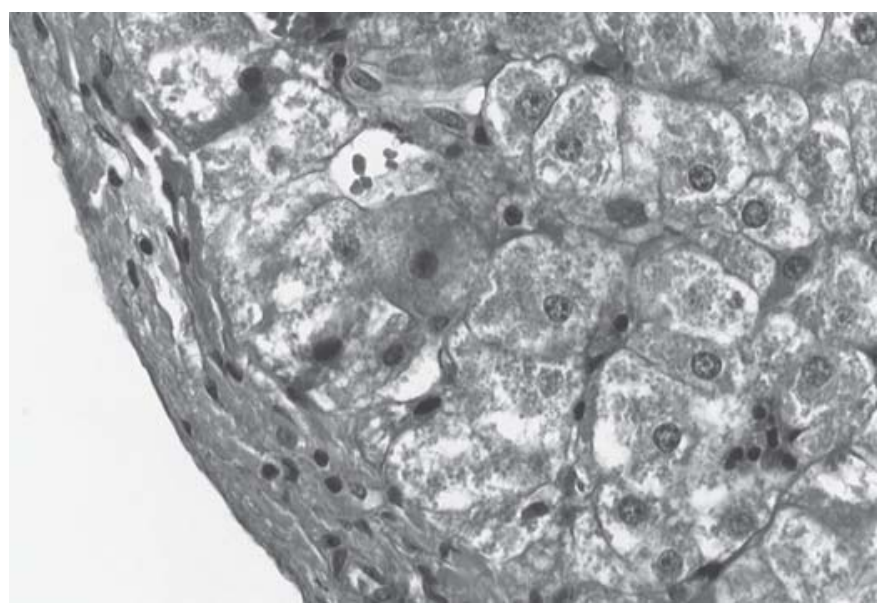

Fig.4. Espessamento da cápsula e severa vacuolização dos hepatócitos subcapsulares no fígado de búfalo. HE, obj.40x.

servada, também, necrose individual de hepatócitos, principalmente na região centrolobular, sendo mais evidente nas regiões onde havia vacuolização acentuada. Discretos infiltrados de células mononucleares, com raros neutrófilos, eram observados distribuídos aleatoriamente, em alguns lóbulos hepáticos. Todos os animais apresentaram espessamento da cápsula e vacuolização moderada a acentuada dos hepatócitos subcapsulares (Fig.4).

Nos linfonodos mesentéricos foi observada infiltração de macrófagos em todas as amostras. Em alguns animais, grandes grupos de macrófagos espumosos infiltravam a maior parte da região medular e alguns grupos eram observados na região cortical (Fig.3). Em outros a infiltração de macrófagos espumosos se estendia difusamente desde a região medular até a cortical, permanecendo apenas as áreas próximas a cápsula sem infiltração.

No fígado dos animais do G3 (12 meses em pastagem de $B$. decumbens) a infiltração por macrófagos espumosos variou de grau 1 a 3. Dos 29 animais, 18 apresentaram grau 1, nove grau 2 e dois grau 3 . A infiltração afetava principalmente a região centrolobular e em menor grau a 


\section{Quadro 1. Número e percentual de animais de cada grupo de acordo com grau de lesão hepática discreta ou acentuada}

\begin{tabular}{|c|c|c|c|c|c|c|c|}
\hline \multirow[t]{2}{*}{ Grupo } & \multirow[t]{2}{*}{ Permanência nas pastagens } & \multicolumn{6}{|c|}{ Infiltração por macrófagos espumosos } \\
\hline & & $\mathrm{G} 1(\mathrm{n})$ & $\mathrm{G} 2(\mathrm{n})$ & $\mathrm{G} 1+\mathrm{G} 2(\%)$ & G3(n) & $\mathrm{G} 4(\mathrm{n})$ & $\mathrm{G} 3+\mathrm{G} 4(\%)$ \\
\hline 1 & Criados em campo nativo & 0 & 0 & 0 & 0 & 0 & 0 \\
\hline 2 & Criados em $B$. brizantha & 3 & 5 & $7,1 a^{*}$ & 6 & 3 & $52,9 a$ \\
\hline 3 & 12 meses em $B$. decumbens & 18 & 9 & $93,1 b$ & 2 & & $6,9 b$ \\
\hline 4 & 18 meses em $B$. brizantha & 1 & 3 & $23,5 a$ & 9 & 4 & $76,5 a$ \\
\hline
\end{tabular}

mediozonal. Somente em cinco amostras foi observada, também, discreta infiltração na região periportal. Foi observada tumefação discreta dos hepatócitos da região centrolobular em todas as amostras e necrose individual de alguns hepatócitos. Discretos infiltrados de células mononucleares, com raros neutrófilos, eram observados em alguns lóbulos hepáticos, distribuídos aleatoriamente. Todos os animais apresentaram leve espessamento da cápsula e discreta vacuolização dos hepatócitos subcapsulares. Nos linfonodos mesentéricos havia grandes grupos de macrófagos espumosos ocupando a maior parte da região medular. Na região cortical eram observados alguns grupos isolados de macrófagos espumosos.

No fígado dos animais do G4 (há 18 meses em pastagem de $B$. brizantha) a infiltração por macrófagos espumosos foi mais severa que a do G3. Dos 17 animais, um apresentava grau 1, três grau 2, nove grau 3 e quatro grau 4. A infiltração era moderada a acentuada nas regiões centrolobulares a mediozonais e discreta na região periportal. Os hepatócitos da região centrolobular estavam aumentados de volume, com citoplasma pálido e vacuolizado, membrana irregular e núcleo pequeno. Essas alterações eram mais acentuadas nos locais onde a infiltração de macrófagos era acentuada (grau 3 ou 4), podendo se estender por quase todo o lóbulo, restando apenas os hepatócitos próximos à região periportal sem alterações. Foi observada também, necrose individual de hepatócitos, principalmente na região centrolobular. A necrose de hepatócitos era mais evidente nas regiões onde havia vacuolização acentuada. Discretos infiltrados de células mononucleares, com raros neutrófilos, eram observados em alguns lóbulos hepáticos, distribuídos aleatoriamente. Todos os animais apresentaram espessamento da cápsula e moderada à acentuada vacuolização dos hepatócitos subcapsulares. Nos linfonodos mesentéricos a infiltração de macrófagos foi observada em todas as amostras. Em alguns animais grandes grupos de macrófagos espumosos infiltravam a maior parte da região medular e alguns grupos eram observados na região cortical. Em outros a infiltração de macrófagos espumosos se estendia difusamente desde a região medular até a cortical, permanecendo apenas as áreas próximas a cápsula sem infiltração.

Os animais do G2 e do G4, que permaneceram um período maior em pastagens de Brachiaria spp., apresentaram lesões mais acentuadas de macrófagos espumosos do que os animais do G3. Quando agrupados os graus de macrófagos espumosos em lesões discretas (graus $1 \mathrm{e}$ 2) e acentuadas (graus 3 e 4 ) houve diferença significativa $(p \leq 0,05)$ entre os grupos $\mathrm{G} 2$ e G3 e G4 e G3, enquanto que entre os grupos G2 e G4 não houve diferença significativa ( $p>0,05$ ) (Quadro 1).

Nos animais do G5 (bovinos mantidos em $B$. brizantha durante aproximadamente 12 meses) foram observados pequenos grupos de macrófagos espumosos nos linfonodos mesentéricos e ausência dessas células no fígado.

Não foi encontrada nos animais dos G2, G3 e G4 diferença significativa entre os graus de lesão de macrófagos espumosos e o peso dos animais ao abate dentro de cada grupo, não sendo observado, portanto, relação entre a presença de macrófagos espumosos e o peso nos animais.

Durante o período de março de 2008 a janeiro de 2010 foi observado apenas um caso de fotossensibilização em bubalinos na área de influência da Faculdade de Veterinária da UFPA. De um lote de 60 animais trazidos da llha de Marajó e introduzidos em uma pastagem de $B$. humidicola, no município de Mojú, um apresentou lesões graves de fotossensibilização cinco meses após a introdução na pastagem.

\section{DISCUSSÃO}

Foi observada grande quantidade de macrófagos espumosos e outras lesões no fígado e linfonodos mesentéricos dos bubalinos dos G2, G3 e G4, mantidos em pastagens de Brachiaria spp. Essas lesões não foram observadas nos bubalinos do G1, mantidos em campos nativos da llha de Marajó, criados sem ingerir Brachiaria spp. Esses resultados sugerem que as lesões hepáticas observados são ocasionadas pela ingestão de Brachiaria spp. Resultados semelhantes foram relatados por Driemeier et al. (1999), que determinaram, pela primeira vez, a relação entre 0 consumo de Brachiaria spp. e a presença de macrófagos espumosos no fígado e linfonodos de bovinos abatidos em frigorífico. A presença destes macrófagos espumosos está associada às saponinas litogênicas contidas nas pastagens, o que é evidenciado pela presença de cristais dentro dos macrófagos (Lemos et al. 1998, Driemeier et al. 1998). Moreira et al. (2009a) encontraram macrófagos espumosos no fígado e gânglios de bovinos alimentados por Andropogon gayanus, planta que também contêm saponinas litogênicas (Castro et al. 2009, Moreira et al. 2009b).

Os animais do G2 e do G4, que permaneceram um período maior em pastagens de Brachiaria spp., apresentaram 
lesões mais acentuadas do que os animais do G3. Achado semelhante foi relatado por Silva (1989) que observou a presença, ainda que incipiente, de células espumosas no fígado de bovinos jovens de 5 a 8 meses, sem sinais de fotossensibilização, enquanto que nos animais mais velhos estas células eram mais evidentes e mais frequentes.

Macrófagos espumosos e outras lesões (tumefação, vacuolização e/ou necrose de hepatócitos e fibrose periportal) semelhantes às observadas neste trabalho são observadas em bovinos abatidos procedentes de pastagens de Brachiaria spp. (Driemeier et al. 1998, Fioravante 1999, Gomar et al. 2005, Moreira et al. 2009). No entanto, pelas descrições desses autores, as lesões em búfalos mantidos em pastagens de Brachiaria spp. são bem mais graves do que as observadas em bovinos. Isto é sugerido, também, pela observação de lesões bem menos marcadas no grupo de 15 bovinos (G5) procedentes também de pastagens de Brachiaria spp. Por outro lado, o fato de existirem poucos relatos de fotossensibilização em bubalinos mantidos em pastagens de Brachiaria spp. indica que esta espécie, apesar de ser sensível à intoxicação por essas gramíneas, é aparentemente mais resistente à intoxicação do que os bovinos, pois raramente apresentam a forma clínica da intoxicação. Talvez essas lesões encontradas no abate, bem mais graves do que as observadas em bovinos, indiquem que esses animais se intoxicam (evidenciado pelas lesões hepáticas), mas não manifestam sinais clínicos podendo ser definidos como animais resilientes. Em bovinos a presença de macrófagos espumosos não tem sido correlacionada com a toxicidade de Brachiaria spp., podendo ser uma conseqüência da ingestão por tempo longo de saponinas litogênicas, sem necessariamente estar associados à quantidade de saponinas ingeridas. No entanto, outras lesões como vacuolização, tumefação e necrose de hepatócitos, têm sido descritas com freqüência, associadas a casos clínicos de intoxicação (Tokarnia \& Langenegger 1983, Button et al. 1987, Alessi et al. 1994, Lemos et al. 1996a,b, 1997, 1998, 2009, Santos Jr 2008, Castro et al. 2009, Mustafa 2009).

Tokarnia \& Langenegger (1983) encontraram grande quantidade de macrófagos espumosos, vacuolização, necrose e tumefação de hepatócitos no fígado de búfalos com fotossensibilização mantidos em pastagens de $B$. humidicola. Após a observação das lâminas desse caso, verificou-se que as lesões foram semelhantes às encontradas nos bubalinos do presente estudo que apresentavam lesões de grau 4. Lesões semelhantes são descritas em um caso de intoxicação por $B$. decumbens em búfalos no Rio Grande do Sul (Rozza et al. 2004). No presente trabalho, apesar de muitos animais apresentarem lesões acentuadas, semelhantes às descritas por esses autores, nenhum apresentava sinais clínicos de fotossensibilização. A presença de lesões histológicas hepáticas relativamente graves, sem sinais clínicos, chama a atenção para a possibilidade de que em búfalos mortos por outras causas essas lesões sejam interpretadas como a causa da morte, levando a um diagnóstico errôneo de intoxicação por Brachiaria spp.
Em bovinos foi encontrada uma correlação negativa entre ganho de peso e o número de macrófagos espumosos em fígados de bovinos pastejando em $B$. decumbens, sugerindo que perdas econômicas importantes ocorreriam em animais sem sinais clínicos (Fioravante 1999, Moreira et al. 2009a). Fagliari et al. (1993) descrevem também uma forma subclínica da doença. Embora no presente estudo não tenha sido observado relação entre o peso dos animais ao abate e a quantidade de macrófagos espumosos no fígado, não é possível descartar que essas lesões ocasionem menores ganhos de peso, constituindo uma forma subclínica da doença. Novos estudos são necessários para determinar a possível interferência destas lesões no ganho de peso de búfalos, assim como a resistência/susceptibilidade dos bubalinos à intoxicação por Brachiaria spp. quando comparado com outras espécies.

Agradecimentos- Trabalho financiado pelo Instituto Nacional de $\mathrm{Ci}$ ência e Tecnologia Para o Controle das Intoxicações por Plantas (Proc. CNPq n $n^{\circ}$ 573534/2008-2. Os autores agradecem ao Professor Carlos Tokarnia pela disponibilização de lâminas histológicas de um caso de fotossensibilização em búfalos.

\section{REFERENCIAS}

Alessi A.C., Fagliari J.J., Okuda H.T. \& Passipieri M. 1994. Intoxicação natural de bovinos pela micotoxina esporidesmina. 4-Lesões hepáticas. Arq. Bras. Med. Vet. Zoot. 46(4):319-328.

Albernaz T.T., Silveira J.A.S., Reis A.B., Oliveira C.H.S., Oliveira C.M.C., Duarte M.D., Cerqueira V.D., Riet-Correa G. \& Barbosa Neto J.D. 2008. Fotossensibilização em ovinos associada à ingestão de Brachiaria brizantha no Pará. Anais Encontro Nacional de Diagnóstico Veterinário, Campo Grande, MS, p.73-74.

Barbosa J.D., Oliveira C.M.C., Tokarnia C.H. \& Peixoto P.V. 2006. Fotossensibilização hepatógena em eqüinos pela ingestão de Brachiaria humidicola (Gramineae) no Estado do Pará. Pesq. Vet. Bras. 26:147-153.

Barbosa J.D. 2009. Comunicação pessoal (Faculdade de Medicina Veterinária, Universidade Federal do Pará, Rua Maximino Porpino da Silva 1000, Castanhal, PA 68743-080).

Brum K.B., Haraguchi M., Lemos R.A.A., Riet-Correa F. \& Fioravante M.C. 2007. Crystal associated cholangiopathy in sheep grazing Brachiaria decumbens containing the saponin protodioscin. Pesq. Vet. Bras. 27:39-42.

Button C., Paynter D.I., Shiel M.J., Colson A.R., Paterson P.J. \& Lyford R. L. 1987. Crystal-associated cholangiohepatopathy and photosensitization in lambs. Aust. Vet. J. 64(6):176-80.

Castro M.B., Santos Jr. H.L, Mustafa V.S., Gracindo C.V., Moscardini A.C.R., Louvandini H., Paludo G.R., Borges J.R.J., Haraguchi M., Ferreira M.B. \& Riet-Correa F. 2009. Brachiaria spp. poisoning in sheep in Brazil: Experimental and epidemiological findings. $8^{\text {th }}$ International Symposium on Poisonous Plants, João Pessoa, Paraíba, Brazil, p.12. (Abstract)

Driemeier D., Barros S.S., Peixoto P.V., Tokarnia C.H., Döbereiner J. \& Brito M.F. 1998. Estudo histológico, histoquímico e ultra-estrutural de fígados e linfonodos de bovinos com presença de macrófagos espumosos ("foam cells"). Pesq. Vet. Bras. 18:29-34.

Driemeier D., Döbereiner J., Peixoto P.V. \& Brito M.F. 1999. Relação entre macrófagos espumosos ("foam cells") no fígado de bovinos e ingestão de Brachiaria spp no Brasil. Pesq. Vet. Bras. 19:79-83.

Fagliari J.J., Passipieri M. \& Oliveira J.A. 1983. Sintomas de fotossen- 
sibilidade em bezerros alimentados com leite materno. Arq. Bras. Med. Vet. Zootec. 35(4):479-484.

Fagliari J.J., Passipieri M., Kuchembuck M.R.G. \& Curi P.R. 1993. Intoxicação natural de bovinos pela micotoxina esporidesmina. II. Aspectos clínicos. Arq. Bras. Med. Vet. Zoot. 45(3):275-282.

Fioravanti M.C. 1999. Incidência, avaliação clínica, laboratorial e anatomopatológica da intoxicação subclínica por esporidesmina em bovinos. Tese de Doutorado, Faculdade de Medicina Veterinária e Zootecnia, Unesp, Botucatu, SP. 256p.

Gomar M.S., Driemeier D., Colodel E.M. \& Gimeno E.J. 2005. Lectin histochemistry of foam cells in tissues of catle grazing Brachiaria spp. J. Vet. Med. Physiol. Pathol. Clin. Med. 52:18-21.

Lemos R.A.A., Osório A.L.A.R., Rangel J.M.R \& Herrero J.R.G.O. 1996a. Fotossensibilização e colangiopatia associada a cristais em bezerros ingerindo Brachiaria brizantha. Arqs Inst. Biológico, São Paulo, 63(Supl.):22.

Lemos R.A.A., Ferreira L.C.L., Silva S.M., Nakazato L. \& Salvador S.C. 1996b. Fotossensibilização e colangiopatia associada a cristais em ovinos em pastagem com Brachiaria decumbens. Ciência Rural 26:109-113.

Lemos R.A.A., Salvador S.C. \& Nakazato L. 1997. Photosensitization and crystal associated cholangiohepatopathy in cattle grazing Brachiaria decumbens in Brazil. Vet. Human Toxicol. 39:376-377.

Lemos R.A.A., Nakazato L., Herrero J.R.G.O., Silveira A.C. \& Porfírio L.C. 1998. Fotossensibilização e colangiopatia associada a cristais em caprinos mantidos sob pastagens de Brachiaria decumbens no Mato Grosso do Sul. Ciência Rural 28:507-510.

Lemos R.A.A., Nogueira A.P.A., Souza R.I.C., Santos B.S., Carvalho N.M., Aniz A.C.M. \& Freitas P.C. 2009. Brachiaria spp. poisoning in ruminants in Mato Grosso do Sul, Brazil. 8 International Symposium on Poisonous Plants, João Pessoa, Paraíba, Brazil, p.98. (Abstracts)

Moreira C.N., Moraes M., Garcia E.C., Neto S.C., Araújo E.G. \& Fioravanti M.C.S. 2009a. Bovinos alimentados com Brachiaria spp e
Andropogon gayanus: alterações histológicas dos fígados e linfonodos. Ciênc. Anim. Bras. 10(1):206-218.

Moreira C.N., Banys V.L., Pinto A.S., Franco L.A.S., Haraguchi M. \& Fioravanti M.C.S. 2009b. Bovinos alimentados com capim Brachiaria e Andropogon: desempenho, avaliação da quantidade de esporos do fungo Pithomyces chartarum e teor de saponinas nas pastagens. Ciênc. Anim. Bras.10(1):184-194.

Mustafa V.S. 2009. Intoxicação por Brachiaria spp. em ovinos no Brasil central. Dissertação de Mestrado em Saúde Animal. Brasília, DF. 71p.

Riet-Correa F. \& Méndez M.C. 2007. Intoxicações por plantas e micotoxinas, p.99-219. In: Riet-Correa F., Schild A.L., Lemos R.A.A. \& Borges J.R.J. (Eds), Doenças de Ruminantes e Eqüídeos. Vol.2. Editora Pallotti, Santa Maria, RS.

Riet-Correa G., Riet-Correa F., Schild A.L. \& Driemeier D. 2002. Wasting and death in cattle associated with chronic grazing of Brachiaria decumbens. Vet. Hum. Toxicol. 44(3):179-180.

Rozza D.B., Seitz A.L., Bandarra P.M., Santos E.O. \& Driemeier D. 2004. Fotossensibilização por Brachiaria decumbens em búfalo. Pesq. Vet. Bras. 24(Supl.):55-56.

Santos Jr H.L. 2008. Estudo da toxicidade de diferentes estágios de crescimento de Brachiaria decumbens em ovinos. Brasília. Dissertação de Mestrado em Saúde Animal, Faculdade de Agronomia e Veterinária, Universidade de Brasília, DF. 70p.

Silva L.B. 1989. Alterações hepáticas em bovinos acometidos de doença periodontal (cara inchada). Tese de Mestrado, Escola de Veterinária, Universidade Federal de Minas Gerais, Belo Horizonte. $27 p$.

Silveira J.A.S., Albernaz T.T., Silva e Silva N., Lopes C.T.A., Cerqueira V.D., Oliveira C.M.C.H., Duarte M.D. \& Barbosa J.D. 2009. Fotossensibilização hepatógena em caprinos associada à ingestão de Brachiaria brizantha no estado do Pará. Ciênc. Anim. Bras. 1(Supl.): 336-441.

Tokarnia C.H. \& Langenegger J. 1983. Relatório de viagem. 9p. (Datilografado) 